\title{
I ntensity of primary emotions in patients after implantation of an implantable cardioverter defibrillator
}

\author{
Louise Stoier ${ }^{1}$, Preben Ulrich Pedersen², Selina Kikkenborg Berg ${ }^{3}$ \\ 1. Department of Cardiology, Bispebjerg University Hospital, Denmark. 2. Centre of Clinical Guidelines Danish National \\ Clearinghouse in Nursing, University of Aalborg, Denmark. 3. The Heart Centre, Rigshospitalet, University of Copenhagen, \\ Denmark.
}

Correspondence: Louise Stoier. Address: Department of Cardiology, Bispebjerg University Hospital, Bispebjerg Bakke 23, 2400 Copenhagen NV, Denmark. E-mail: Lsto0029@regionh.dk.

Received: November 14, 2012

Accepted: December 9, 2012

Online Published: January 22, 2013

DOI : $10.5430 /$ jnep.v3n8p18

URL: http://dx.doi.org/10.5430/jnep.v3n8p18

\section{Abstract}

Background: Experienced emotions can affect the outcome of, and adherence to a cardiac rehabilitation program, and patients coping with an illness. With more awareness of the expressed emotions, health professionals might be better able to understand the reactions of patients and to improve the support needed for coping. Living with an Implantable Cardioverter Defibrillator can lead to anxiety and depression. Focus on the intensity of the primary emotions might be a potential to prevent development of these psychological states.

Objectives: The aim of this paper are 1) to describe the intensity of primary emotions in patients after implantation of an Implantable Cardioverter Defibrillator and 2) to compare them with both the intensity of primary emotions in patients with a recent Myocardial Infarction and with a healthy population.

Method: The intensity of primary emotions in patients receiving an Implantable Cardioverter Defibrillator was measured by a survey using the Emotions and Health Scale. The survey was carried out as part of a randomized clinical trial the COPE-ICD trial (ID: NCT00569478) and is regarded as post-hoc explorative analysis. All data were collected from October 2007-November 2009. A total number of 154 patients were needed in the trial. The data collected were compared with secondary data from patients who had recently suffered a Myocardial Infarction and from a healthy population. SPSS version 18.0 was used to analyze the data using $t$-test, chisquare and F-test.

Results: One hundred and ninety-six patients were invited to fill in the questionnaire. It was completed by 182, a response rate of $93 \%$. Patients with a newly implanted Implantable Cardioverter Defibrillator experienced an increased intensity of joy, sadness, disgust, anticipation, anger, fear and surprise. No difference was found regarding the intensity of the primary emotions when the group of patients was divided according to occupation or age. A significant increase in the negative emotions sadness, disgust, anger and surprise was observed in women and in patients who receive the Implantable Cardioverter Defibrillator as a secondary prevention. The combination of increased senses of fear and surprise is unique to patients receiving an Implantable Cardioverter Defibrillator. The intensity of the primary emotions in patients with a newly implanted Cardioverter Defibrillator was comparable to the intensity in patients with a myocardial infarction, but the experience of anticipation and fear was markedly increased in patients with an Implantable Cardioverter Defibrillator.

Conclusion: Women and patients who receive an Implantable Cardioverter Defibrillator as secondary prevention experience a significant increase in the negative emotions sadness, disgust, anger and surprise. 


\section{Key words}

Emotions, Implantable Cardioverter Defibrillator, The emotion and health scale, Anxiety, Depression

\section{I ntroduction}

An essential task in health care is to support patients who must adapt to a new life situation. To understand their emotional reactions and their importance for coping with an illness, it is necessary to identify the experienced emotions during this time.

To report a patient's response to an illness it is usual to refer to their reaction or emotional status, and often health professionals describe patients as "anxious" or "depressed" ${ }^{[1]}$. Thereby pathological terms are used to describe the patient's emotional reaction. However anxiety and depression may be related to the basic emotions ${ }^{[2-4]}$. From this perspective the best way to prevent patients from developing anxiety and depression during their recovery after an illness is to focus on the precursor (emotions) rather than the possible outcome (anxiety and depression) ${ }^{[5]}$.

\subsection{Emotions and illness}

Emotions are an integral and important part of human existence. Despite a fundamental acceptance of emotions as a significant part of the human condition, there is little factual knowledge about how the emotions influence the way humans master an illness process ${ }^{[1]}$. Illness can be an unpleasant experience and the accompanying experiences will inevitably lead to a fundamental reaction ${ }^{[5]}$. It might be that most patients emotional reactions are a defence, linked to a healthy survival strategy. These reactions may give expression to patients' needs for coping ${ }^{[1]}$.

The experienced emotions can affect the outcome of and adherence to a rehabilitation program. Psychological distress can influence patients' adherence and improvement in cardiac rehabilitation ${ }^{[6,7]}$. One study found that patients who were emotionally affected after a myocardial infarction adhered more closely to a rehabilitation program ${ }^{[8]}$.

How patients cope with illness is also affected by their experienced emotions. Patients with higher scores of mood disturbance have been found to be more impacted by stress and have difficulty in coping with an injury ${ }^{[9]}$ or in adapting to life with an Implantable Cardioverter Defibrillator (ICD) ${ }^{[10]}$.

\subsection{Living with an ICD}

Treatment with ICD has reduced mortality remarkably during the past 20 years. This has resulted in new, more extensive guidelines for the implantation of ICDs ${ }^{[11-14]}$.

The implantation of an ICD eliminates a part of the fear of sudden cardiac arrest, but can cause new fear and lifestyle limitations ${ }^{[15]}$. Living with an ICD can lead to anxiety, depression, fear and avoidance of situations, places and objects that patients associate with ICD shock. This has often led to social isolation, avoidance of physical activity, including sexual activity and mood disturbances ${ }^{[16-21]}$. Some patients are at risk of poor psychological adaptation attributable to their personality profile ${ }^{[22]}$. Furthermore negative emotions might be the cause rather than the result of arrhythmia, and that psychological stress and distress can increase the risk of shock ${ }^{[23,24]}$. In addition posttraumatic stress disorder has been identified as a serious mortality risk for patients living with an $\mathrm{ICD}^{[25]}$.

\subsection{Primary emotions}

Symptoms of anxiety and depression are used in many studies to appraise experienced emotions. These psychological states develop based on a complex combination of emotions and thoughts, whereas for example fear and sadness are welldefined emotions connected with a specific experience in life ${ }^{[26]}$.

Emotion theorists ${ }^{[27,28]}$ describe emotions as a basic set of influences, each with unique variations shaped by individual experiences. Each emotion has a functional or adaptive property specific to the continually changing environment ${ }^{[1]}$. 
Plutchik ${ }^{[29]}$ identified eight primary emotions: joy, sadness, agreeableness, disgust, anticipation, anger, fear and surprise. According to Plutchik ${ }^{[29]}$, these "basic" emotions are biologically primitive and have evolved in order to increase the reproductive fitness of the animal. The concept primary is used as these emotions are fundamental for all other emotions.

Knowledge and accurate identification of the emotional consequences of illness can help nurses support the patient during recovery ${ }^{[1]}$. Sadness, anger, disgust and surprise are considered to be negative emotions, and a remaining increased intensity of these emotions might lead to development of anxiety and depression (see Table 1$)^{[5]}$. With more awareness of expressed emotions, health professionals might be better able to understand patients' reactions and to improve the support needed for coping with illness. The purpose of this study was to identify the primary emotions in patients after implantation of an ICD and to illuminate whether the experienced emotions differ from other populations.

Table 1. Primary emotions according to Plutchik ${ }^{[28,29]}$

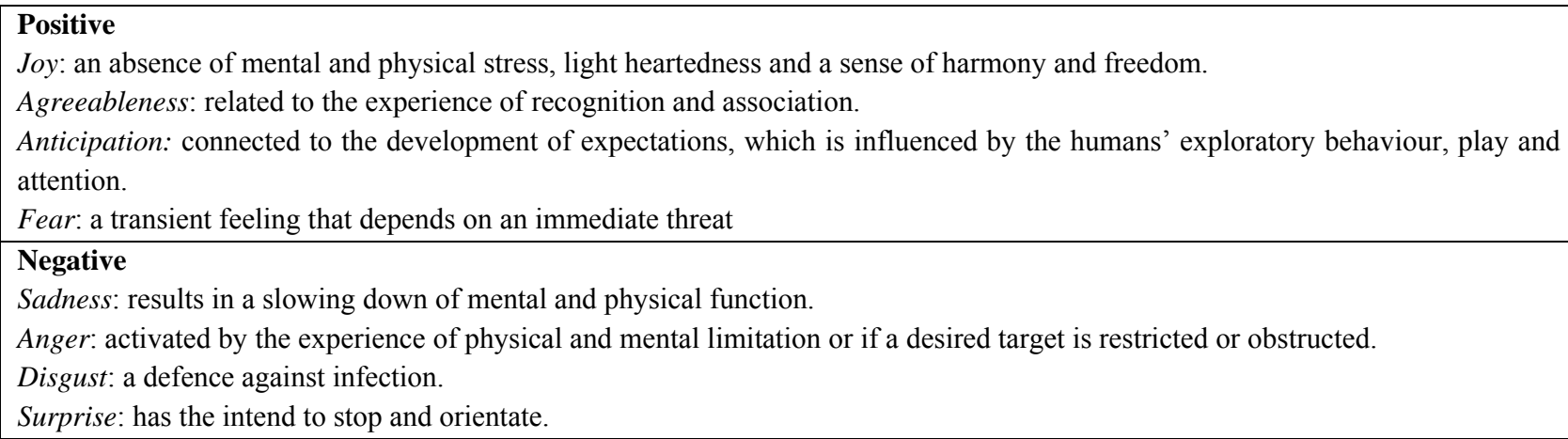

The survey was administered as part of the COPE-ICD trial ${ }^{[30]}$ and was examined as post-hoc explorative analysis. The COPE-ICD trial was a randomized clinical trial that examined the effects and meaning of a comprehensive rehabilitation program for ICD recipients ${ }^{[30]}$. The setting for the COPE-ICD trial was a large university hospital with a volume of approximately 300 first time ICD implantations every year.

\section{Method}

The aims of the present study were to:

1) Describe the intensity of primary emotions in patients after implantation of an ICD.

2) Compare the intensity of primary emotions in patients with an ICD with the intensity of primary emotions in patients with a recent Myocardial Infarction (MI) and a healthy population.

\subsection{Design}

The Emotion and Health Scale was used in the COPE-ICD trial to examine the potential effects of rehabilitation on primary emotions and to describe the trajectory of primary emotions over time in patients with ICD. This paper is a report on the baseline measures of the Emotion and Health Scale. The outcome of the COPE-ICD trial concerning the primary emotions will be published in a future paper.

The data from patients after a MI and a healthy population are drawn from an English study where the Emotion and Health Scale was used ${ }^{[5]}$. In the English study a cohort of 150 healthy university students and 80 patients with a first-time MI was enrolled.

\subsection{Inclusion}

Patient who received an ICD for the first time, and who agreed to participate in the entire program, was included in the trial prior to hospital discharge. 


\subsection{Exclusion}

- Patients who did not understand the study instructions.

- Patients under the age of 18 .

- Patients who were diagnosed with a psychiatric disease.

- Patients with other somatic disease, where recovery might influence the study.

- Patients who were not given permission by their physician to participate in the physical training program were excluded before randomization.

Due to local policies, patients were not asked to participate if they were eligible for pharmaceutical trials. Reasons for not fulfilling inclusion criteria were: other somatic diseases $(n=49)$, psychiatric disease or cognitive dysfunction $(n=20)$, language $(\mathrm{n}=11)$. A total of 196 patients were included during the inclusion period.

\subsection{The Emotion and health scale}

The Emotion and Health Scale was developed ${ }^{[5]}$ based on a functionalistic theory of emotions ${ }^{[2]}$. The scale is based on the assumption that each emotion influences the behaviour of individuals and evokes different motivational goals, which directly affect the adaptation to the new situation. The questionnaire measures the intensity of the primary emotions of the respondent.

The Emotion and Health Scale consists of 24 questions that represent the eight primary emotions. Each emotion is identified by three questions with five possible answers. The possible answer ranks the intensity of experienced emotions from "not at all" to "intensely". The questionnaire response "not at all" was given the value 1 and "intensely" had the value 5. In determining data were the values of the three questions that all represented the same feeling merged, why the total minimum score for each emotion is 3 and maximum score is 15 .

\subsection{Validity and reliability}

The Emotion and Health Scale has been validated in several ways ${ }^{[5]}$. Construct validity was checked by comparing a healthy group of students with a group of patients with myocardial infarction. Content validity was checked by having a panel of experts critically review each statement in the questionnaire and verify the relation to each emotion. The questionnaire was face-content validated by a pilot-study.

To use the Emotion and Health Scale in a Danish context the questionnaire was translated into Danish. To validate the translated material the questionnaire was translated back into English by a non-involved translator so that discrepancies could be identified and corrected ${ }^{[32]}$. The reliability of the translated questionnaire was tested by Cronbach's alfa for each of the eight emotions. It ranged from 0.32 to 0.75 .

\subsection{Data collection}

The Emotion and Health Scale was distributed to all enrolled subjects together with all baseline questionnaires from the COPE-ICD trial ${ }^{[30]}$ while the patients were hospitalized for ICD implantation. All questionnaires were collected again before patients were discharged, resulting in a response rate of $93 \%$. Demographic and clinical data were also collected during the hospitalization. A blinded investigator performed data collection and administration.

\subsection{Ethical considerations}

The trial was approved by the regional Ethics Committee (j.nr. H-B-2007-014), National Data Security (j.nr. 2007-41 -0932) and registered at Clinical Trials.gov (ID: NCT00569478). Patients were asked to participate in the study after receiving oral and written information, and were given time to reflect on their participation before given written informed 
consent. All data material was treated in confidence and patients were assured anonymity. The study follows the recommendations of the Declaration of Helsinki II ${ }^{[31]}$.

\subsection{Data analysis}

Questionnaire responses were converted to numerical scores using standard methodologies ${ }^{[32]}$. SPSS version 18.0 was used to analyze the data. Statistical significance was set at $p<0.05$. Continuous data were checked for normality of distribution by F-test. The baseline characteristics are presented by number and percentage. The mean scores of the 8 subscales in the Emotion and Health Scale were calculated. Then comparisons were made by two independent sample T-tests for the mean difference between two independent samples e.g. indication, job, age, sex and LVEF. To check for non-response bias a response analysis using T-test and $\chi^{2}$-test was carried out by gender, job, indication and age.

\section{Results}

\subsection{Demographics}

Characteristics of patients included are given in Table 2. Mean age was 58.4; $79 \%$ was men and $66 \%$ of the population had the ICD implanted as primary prevention of sudden cardiac death $(95 \% \mathrm{CI}=59.9-73.5)$.

Table 2. Baseline demographic and clinical variables

\begin{tabular}{|c|c|c|}
\hline Variables & $\begin{array}{l}\text { Patients included in COPE- } \\
\text { ICD }(n=196)\end{array}$ & $\begin{array}{l}\text { Total of patients receiving an ICD in Denmark } \\
\text { October } 2007 \text { - November } 2009 \text { ( }(n=2066)\end{array}$ \\
\hline Age (years), mean (SD) & $58.4(13.1)$ & 62.3 \\
\hline \multicolumn{3}{|l|}{ Demographics variables } \\
\hline \multicolumn{3}{|l|}{ Sex n $(\%)$} \\
\hline Female & $41(21)$ & $434(21)$ \\
\hline Male & $155(79)$ & $1632(79)$ \\
\hline \multicolumn{3}{|l|}{ In job, n (\%) } \\
\hline Yes & $91(46)$ & \\
\hline No (retired or unemployed) & $103(53)$ & \\
\hline Not indicated & $2(1)$ & \\
\hline \multicolumn{3}{|l|}{ Clinical variables } \\
\hline \multicolumn{3}{|l|}{ Indication, $\mathrm{n}(\%)$} \\
\hline Primary & $130(66)$ & $1069(52)$ \\
\hline Secondary & $66(34)$ & $997(48)$ \\
\hline \multicolumn{3}{|l|}{ Symptoms: } \\
\hline Atrial fibrillation & $48(25)$ & \\
\hline Ventricular fibrillation & $40(20)$ & \\
\hline NYHA I & $48(25)$ & \\
\hline NYHA II & $86(44)$ & \\
\hline NYHA III & $56(29)$ & $421(20)$ \\
\hline NYHA IV & 3 (2) & \\
\hline History of HF & $149(76)$ & \\
\hline Hypertension & $41(21)$ & \\
\hline
\end{tabular}




\subsection{Response analysis}

The response analysis showed no significance between respondents and non-respondents (gender: $p=0.74$, job: $p=0.79$, indication: $p=0.56$ and age: $p=0.37$ ).

\subsection{I ntensity of primary emotions}

Table 3 shows the mean scores of the collected data from the survey. The data from patients after a MI and a healthy population are drawn from an English study where the Emotion and Health Scale was used ${ }^{[5]}$. Compared to the healthy population the intensity of all the experienced feelings, except agreeableness, is increased in patients after receiving an ICD. The experience of joy, anger and surprise is not significantly different for patients receiving an ICD and after a MI.

Table 3. Differences between patients receiving an ICD, patients after a MI and healthy students

\begin{tabular}{lclcl}
\hline & ICD (SD) & 95 \% CI & MI (SD)* & University-students (SD)* $^{*}$ \\
\hline Joy & $10.7(3.4)$ & $10.2-11.3$ & $10.7(1.8)$ & $9.3(2.2)$ \\
Sadness & $8.9(3.0)$ & $8.4-9.3$ & $8.3(3.3)$ & $4.3(1.5)$ \\
Agreeableness & $8.7(3.4)$ & $8.2-9.2$ & $10.6(2.4)$ & $9.0(2.0)$ \\
Disgust & $5.9(2.9)$ & $5.4-6.3$ & $7.3(3.2)$ & $4.4(1.6)$ \\
Anticipation & $10.1(2.9)$ & $9.7-10.5$ & $7.4(1.7)$ & $7.4(2.0)$ \\
Anger & $7.4(5.1)$ & $6.6-8.1$ & $7.9(3.6)$ & $3.8(1.4)$ \\
Fear & $7.5(2.1)$ & $7.2-7.9$ & $6.6(2.2)$ & $4.9(1.9)$ \\
Surprise & $9.7(3.0)$ & $9.2-10.1$ & $9.5(2.7)$ & $4.9(1.6)$ \\
\hline
\end{tabular}

*significance calculated using non-parametric test

Table 4. Differences between scores on The Emotions and Health Scale of patients receiving an ICD

\begin{tabular}{|c|c|c|c|c|c|c|c|c|}
\hline Variables & Joy & Sadness & Agreeableness & Disgust & Anticipation & Anger & Fear & Surprise \\
\hline \multicolumn{9}{|l|}{ Sex } \\
\hline $\begin{array}{l}\text { Male(SD) } \\
n=143\end{array}$ & $11.2(3.3)$ & $8.4(2.9)$ & $9.3(3.2)$ & $5.4(2.6)$ & $9.9(2.7)$ & $6.6(3.0)$ & 7.2(1.7) & $9.6(2.9)$ \\
\hline $\begin{array}{l}\text { Female(SD) } \\
\mathrm{n}=39\end{array}$ & $9.1(3.5)$ & $10.6(2.8)$ & $6.5(3.2)$ & $7.5(3.3)$ & $10.9(3.2)$ & $10.1(9.1)$ & $8.9(2.9)$ & $10.1(3.2)$ \\
\hline$P$ & 0.001 & $<0.001$ & $<0.001$ & $0.001 *$ & 0.048 & $0.028 *$ & $0.001^{*}$ & 0.324 \\
\hline \multicolumn{9}{|l|}{ Indication } \\
\hline $\begin{array}{l}\text { Primary(SD) } \\
\mathrm{n}=122\end{array}$ & $10.8(3.5)$ & $8.5(2.9)$ & $8.9(3.5)$ & $5.5(2.7)$ & $9.8(2.8)$ & $6.8(3.3)$ & $7.2(2.1)$ & $9.2(3.0)$ \\
\hline $\begin{array}{l}\text { Secondary(SD) } \\
\mathrm{n}=60\end{array}$ & $10.6(3.3)$ & $9.7(2.9)$ & $8.2(3.0)$ & $6.5(3.0)$ & $10.6(2.8)$ & $8.4(7.5)$ & $8.1(2.3)$ & $10.7(2.7)$ \\
\hline$P$ & 0.77 & 0.015 & 0.177 & 0.036 & 0.068 & 0.061 & $0.018^{*}$ & 0.002 \\
\hline \multicolumn{9}{|l|}{ LVEF } \\
\hline $\begin{array}{l}<35(\mathrm{SD}) \\
\mathrm{n}=119\end{array}$ & $11(3.5)$ & $8.7(2.8)$ & $8.8(3.6)$ & $5.7(2.7)$ & $10.2(2.8)$ & $7.5(5.8)$ & $7.3(1.8)$ & $9.5(3.0)$ \\
\hline $\begin{array}{l}\geq 35 \\
\mathrm{n}=61\end{array}$ & $10.4(3.4)$ & $9.2(3.2)$ & $8.3(3.0)$ & $6.2(3.2)$ & $9.9(3.1)$ & $7.2(3.7)$ & $8.1(2.6)$ & $10.0(2.9)$ \\
\hline$P$ & 0.28 & 0.32 & 0.37 & $0.25 *$ & 0.43 & $0.66^{*}$ & 0.02 & 0.36 \\
\hline
\end{tabular}

*significance calculated using non-parametric test

\subsection{Differences according to gender, job, age, indication and ejection- fraction}

There were no significant results found when the group of patients receiving an ICD was divided according to employment status or not. To investigate whether age had an influence on the intensity of the primary emotions, the results were divided according to the age of the included patients. The age of 65 was applied, since 65 is the retirement age in Denmark. There 
was no significant difference found in the intensity of the primary emotions according to age. Table 4 shows the results from patients receiving an ICD divided according to gender, indication and left ventricular ejection-fraction.

\section{Discussion}

This study was a survey investigating the intensity of primary emotions in patients after implantation of an ICD. We found that all primary emotions except agreeableness were increased after implantation of an ICD, when the results were compared to the intensity of primary emotions in a healthy population. Gender was found to be an important variable, since there was a significant difference in the intensity of most of the primary emotions between men and women. Indication for receiving the ICD was also found to effect which primary emotions were intensified. Patients who received the ICD for primary indication experienced less increase in the negative emotions, then patients receiving the ICD as secondary indication.

\subsection{The intensity of the primary emotions}

The experience of joy can be seen as a normal reaction for both patients who just received an ICD and patients after a MI, since the intensity of joy is elevated compared to the healthy group of students.

Both patients receiving an ICD and patients who recently experienced a MI reported an increased intensity of sadness compared to the healthy group of students. An increased level of concern or sadness just before and after implantation of an ICD has earlier been reported ${ }^{[19]}$.

When the results from our survey are compared to the results from the study by Bowman, Watson and Trotman-Beasty ${ }^{[5]}$ it confirms that the feeling of agreeableness does not change significantly during either the experience of an MI or implantation of an ICD.

The emotion of disgust is significantly increased for patients after an MI, but not for patients who newly received an ICD. One could imagine that having a foreign object like an ICD implanted would lead to disgust, but this assumption cannot be confirmed in this study. Studies of the experience of living with an ICD do not report the experience of disgust; however concern with regard to living with an implanted aid is reported ${ }^{[33]}$.

The experience of anticipation is markedly increased for patients after an ICD implantation compared to the healthy group of students and patients after a MI. Implantation of an ICD eliminates the immediate fear of sudden cardiac death ${ }^{[34]}$ and it is likely that the experience of fear would be replaced by the experience of anticipation. However, we found that both the experience of fear and anticipation is elevated in patients after receiving the ICD. Fear of future shocks has been reported, regardless of whether patients had experienced a shock from the $\mathrm{ICD}^{[35]}$. The experience of fear has been reported to be increased when measured three and twelve months after implantation of an ICD ${ }^{[36]}$.

The combination of an increased sense of fear and surprise is unique to patients with ICD, compared to the healthy group and the patients with MI. From this it seems like rehabilitation programs for patients with a newly implanted ICD ought to focus on how to inform and support the patients during their recovery. The experience of negative emotions might lead to increased risk of shock from the ICD ${ }^{[23,24]}$, therefore the observation of the increased intensity of fear and surprise indicates a need for increased attention for these patients during their recovery.

The intensity of anger is increased for both groups of patients with heart diseases compared to the healthy group of students. On the Emotion and Health scale the intensity of anger is explored by questions that specifically ask about the patient's current health situation and not to the patient's experience of the hospital stay or the health care system, which the patient also might direct his or her anger against. The experience of anger in patients after implantation of an ICD has been described in a study, where the patients outline the feeling of being irritated and dissatisfied with themselves and of having difficulty accepting the body's physical weakness. The feeling of being confronted with this physical limitation triggered 
anger among the patients ${ }^{[37]}$. According to the results of our survey anger must be seen as a normal reaction for patients receiving an ICD.

\subsection{Differences in the primary emotions in patients after ICD implantation}

Gender: This study found a significant difference in the intensity of the primary emotions between men and women, with women experiencing a significant increase in the intensity of negative emotions compared to men. Lately there has been more focus on the meaning of the gender in relation to the symptoms and prognosis of heart diseases ${ }^{[38]}$. Women are more emotionally affected by the implantation of an ICD than men and report a higher score of mood disturbance which might affect the rehabilitation process ${ }^{[10]}$. Female gender is considered to be an independent risk factor for development of anxiety after implantation of an ICD ${ }^{[39]}$. It has been found that women do have an increased risk of developing anxiety and depression ${ }^{[19,40]}$, but the opposite result has also been reported ${ }^{[41]}$, and in another study only the development of anxiety was related to female gender ${ }^{[42]}$. More research is needed to explore the meaning of gender in relation to the development of anxiety and depression after implantation of an ICD. The findings in this survey confirm that women seem to be differently emotional affected by the implantation of the ICD compared to men.

ICD indication: The indication for treatment with ICD is divided into primary prevention and secondary prevention. The prehistory for patients who receives an ICD can therefore be very different. Some patients can have experienced sudden cardiac arrest or have a history of extensive electrophysiology testing or medical treatment. Other patients might never have experienced any symptoms. We found that patients who received the ICD as secondary prevention had a significantly higher score according for the negative emotions; sadness, disgust, anger and surprise than patients who received the ICD as primary prevention. The results of our study are comparable to other studies reporting patients receiving an ICD as secondary prevention to be emotionally affected ${ }^{[33]}$.

Age: In the study of the intensity of the primary emotions just after implantation of an ICD we found no difference in the results according to age. Whether age has a meaning for how patients react to the life with an ICD has been the focus for many studies ${ }^{[17,19,22,43,44]}$, none of these studies reports a difference according to the experience of psychological distress right after the implantation of the ICD. In those studies that found a difference according to age, this difference was observed a while after the implantation.

Ejection-fraction: The only significant difference observed when the patients were divided according to ejection-fraction was the experience of fear. Patients with an ejection-fraction $\geq 35$ reported a higher intensity of fear then patients with ejection-fraction $<35$. Decreased ejection-fraction has been reported to lead to anxiety, depression and concern ${ }^{[42]}$, but again the opposite result has also been reported ${ }^{[25]}$. Fear can be misinterpreted by health professionals as anxiety ${ }^{[1]}$. In this context it would have been expected that the intensity of fear in patients with decreased ejection-fraction would have been increased compared to patients with an ejection-fraction $\geq 35$ but this was not the case in this survey.

\section{Limitations of the study}

Baseline characteristics for the included patients are compared with data from the Danish ICD Register in Table 2. The distribution of men and women was identical in the two groups, but according to indication for receiving the ICD, more included patients received the ICD for primary prevention ( $66 \%$; $95 \%$ CI $59.9-73.5$ versus $52 \%$ ). The patients included in the trial had a mean age of 58.4 while the mean age of the total group of patients receiving an ICD was 62.3 . Since the survey was a part of the COPE-ICD trial, patients who decided to participate, agreed to attend an outpatient program including psycho-educational consultations and exercise training ${ }^{[30]}$. This circumstance might affect the decision about participation and thereby the Emotion and Health Scale score. 
The testing for reliability of the translated version of the Emotion and Health Scale ensured that the obtained value for anticipation, anger, fear and surprise can be discussed. The developer of the Emotion and Health Scale ${ }^{[5]}$ reports a Cronbach's alfa $>0.8$ for the entire scale, but for the internal consistency they found it not to acceptable for the emotional dimensions in the students and only for half of the emotional dimensions in the patients with MI. In our trial the questionnaire was tested on a larger population and still we see a low Cronbach's alfa on some of the emotional dimensions.

\section{I mplications for practice and future research}

If the increased intensity of the primary emotions can lead to depression and anxiety ${ }^{[5]}$ and negative emotions and psychological stress can increase the risk of shock from the $\mathrm{ICD}^{[23,40]}$, patients with a newly implanted ICD have an increased need for attention, since these patients experience an increased intensity of primary emotions. Therefore the development of the intensity has to be monitored and the patients should be supported during their recovery. By focusing on the intensity of the primary emotions there might be a potential to prevent the negative effect of the experienced emotions to develop into mental disorders such as anxiety and depression. How health professionals can support patients during their recovery to prevent the negative emotions from developing into anxiety and depression is a field that needs to be explored.

To use the Emotion and Health Scale in practice, the tool needs to be developed and validated further to evaluate reliability in other populations.

\section{Conclusion}

The major findings from this study indicate that patients after receiving an ICD experienced an increased intensity of joy, sadness, disgust, anticipation, anger, fear and surprise. The intensity of the primary emotions in patients with a newly implanted ICD was comparable to the intensity in patients with MI, but the experience of anticipation and fear was markedly increased in patients with an ICD. Furthermore the combination of an increased intensity of fear and surprise was unique to patients who had received an ICD.

A significant increase in the negative emotions sadness, disgust, anger and surprise was observed in women and in patients who received the ICD as a secondary prevention.

\section{Acknowledgment}

The COPE-ICD trial was funded by the Novo Nordisk Foundation, the Oticon Foundation, the Danish Heart Foundation, the AP Møller and Chastine Mc-Kinney Møller Foundation, Helsefonden, the Tryg Foundation, the Augustinus Foundation, the Danish Cardiovascular Research School (DaCRA), Krista and Viggo Petersens Foundation, King Christian the 10th Foundation and Copenhagen University Hospital, Rigshospitalet. None of the funders was involved in the trial.

\section{References}

[1] Bowman GS. Emotions and illness. Journal of Advanced Nursing. 2001; 34(2): 256-263. PMid:11430288 http://dx.doi.org/10.1046/j.1365-2648.2001.01752.x

[2] Gray JA. The psychology of fear and stress. 2. ed. Cambridge: Cambridge University Press; 1987.

[3] Panksepp J. Neurochemical control of moods and emotions: amino acids to neuropeptides. In: Lewis M, Haviland JM, editors. Handbook of emotions New York: Guilford Press; 1993. p. 87.

[4] Wolpert L. Malignant sadness: The anatomy of depression. New York: Free Press; 1999. 
[5] Bowman G, Watson R, Trotman-Beasty A. Primary emotions in patients after myocardial infarction. Journal of Advanced Nursing 2006; 53(6): 636-645. PMid:16553672 http://dx.doi.org/10.1111/j.1365-2648.2006.03770.x

[6] McGrady AA. Effects of depression and anxiety on adherence to cardiac rehabilitation. Journal of Cardiopulmonary Rehabilitation and Prevention. 2009; 29(6): 358-364. PMid:19940639

[7] Glazer KM, Emery CF, Frid DJ, Banyasz RE. Psychological Predictors of Adherence and Outcomes among Patients in Cardiac Rehabilitation. Journal of Cardiopulmonary Rehabilitation. 2002 January/February; 22(1): 40-46. PMid:11839996 http://dx.doi.org/10.1097/00008483-200201000-00006

[8] Whitmarsh A, Koutantji M, Sidell K. Illness perceptions, mood and coping in predicting attendance at cardiac rehabilitation. British Journal of Health Psychology. 2003; 8(2): 209-221. PMid:12804334 http://dx.doi.org/10.1348/135910703321649178

[9] Albinson CB, Petrie TA. Cognitive Appraisals, Stress, and Coping: Preinjury and Postinjury Factors Influencing Psychological Adjustment to Sport Injury. Journal of Sport Rehabilitation. 2003 Nov; 12(4): 306-322.

[10] Dunbar SB, Jenkins LS, Hawthorne M, Porter LS. Mood disturbance in patients with recurrent ventricular dysrhythmia before insertion of implantable cardioverter defibrillator. Heart \& Lung. 1996; 25(4): 253-261.

[11] Zipes DP. ACC/AHA/ESC 2006 Guidelines for Management of Patients With Ventricular Arrhythmias and the Prevention of Sudden Cardiac Death: a report of the American College of Cardiology/American Heart Association Task Force and the European Society of Cardiology Committee for Practice Guidelines (writing committee to develop Guidelines for Management of Patients With Ventricular Arrhythmias and the Prevention of Sudden Cardiac Death): developed in collaboration with the European Heart Rhythm Association and the Heart Rhythm Society. Circulation (New York, N.Y.) 2006 -09-05; 114(10): e385.

[12] Epstein AE, DiMarco JP, Ellenbogen KA et al. Developed in Collaboration With the American Association for Thoracic Surgery and Society of Thoracic Surgeons. ACC/AHA/HRS 2008 Guidelines for Device-Based Therapy of Cardiac Rhythm Abnormalities: Executive Summary: A Report of the American College of Cardiology/American Heart Association Task Force on Practice Guidelines (Writing Committee to Revise the ACC/AHA/NASPE 2002 Guideline Update for Implantation of Cardiac Pacemakers and Antiarrhythmia Devices). Circulation. 2008 May 27; 117(21): 2820-2840. Available from: http://guidelines.gov/content.aspx?id=12590. http://dx.doi.org/10.1161/CIRCUALTIONAHA.108.189741

[13] Goldenberg I, Gillespie J, Moss AJ, Hall W J, Klein H, McNitt S, Brown MW, Cygankiewicz I, Zareba W, the Executive Committee of the Multicenter Automatic Defibrillator Implantation Trial I.I. Long-Term Benefit of Primary Prevention With an Implantable Cardioverter-Defibrillator: An Extended 8-Year Follow-Up Study of the Multicenter Automatic Defibrillator Implantation Trial II. Circulation. 2010 September 28; 122(13): 1265-1271. PMid:20837894 http://dx.doi.org/10.1161/CIRCULATIONAHA.110.940148

[14] Corrado D, Calkins H, Link MS, Leoni L, Favale S, Bevilacqua M, et al. Prophylactic Implantable Defibrillator in Patients With Arrhythmogenic Right Ventricular Cardiomyopathy/Dysplasia and No Prior Ventricular Fibrillation or Sustained Ventricular Tachycardia. Circulation. 2010 September 21; 122(12): 1144-1152. PMid:20823389 http://dx.doi.org/10.1161/CIRCULATIONAHA.109.913871

[15] Tagney J. A literature review comparing the experiences and emergent needs of adult patients with permanent pacemakers (PPMs) and implantable cardioverter defibrillators (ICDs). Journal of Clinical Nursing. 2010; 19(15-16): 2081-2089.

[16] Sears SF, Sowell LD, Kuhl EA, Kovacs AH, Serber ER, Handberg E, et al. The ICD shock and stress management program: a randomized trial of psychosocial treatment to optimize quality of life in ICD patients. Pacing \& Clinical Electrophysiology. 2007; 30(7): 858-864.

[17] Crossmann A, Schulz SM, Kuhlkamp V, Ritter O, Neuser H, Schumacher B, et al. A randomized controlled trial of secondary prevention of anxiety and distress in a German sample of patients with an implantable cardioverter defibrillator. Psychosomatic Medicine. 2010 Jun; 72(5): 434-441. PMid:20410252 http://dx.doi.org/10.1097/PSY.0b013e3181d9bcec

[18] Lewin RJ, Coulton S, Frizelle DJ, Kaye G, Cox H. A brief cognitive behavioural preimplantation and rehabilitation programme for patients receiving an implantable cardioverter-defibrillator improves physical health and reduces psychological morbidity and unplanned readmissions. Heart. 2009; 95(1): 63-69. PMid:18070951 http://dx.doi.org/10.1136/hrt.2007.129890

[19] Bilge AK, Ozben B, Demircan S, Cinar M, Yilmaz E, Adalet K. Depression and anxiety status of patients with implantable cardioverter defibrillator and precipitating factors. Pacing \& Clinical Electrophysiology. 2006; 29(6): 619-626.

[20] Lemon J, Edelman S, Kirkness A. Avoidance behaviors in patients with implantable cardioverter defibrillators. Heart \& Lung: The Journal of Acute and Critical Care. 2004; 33(3): 176-182.

[21] Pedersen SS, van Domburg RT, Theuns DAMJ, Jordaens L, Erdman RAM. Type D Personality Is Associated With Increased Anxiety and Depressive Symptoms in Patients With an Implantable Cardioverter Defibrillator and Their Partners. Psychosomatic Medicine. 2004 September/October; 66(5): 714-719. PMid:15385696 http://dx.doi.org/10.1097/01.psy.0000132874.52202.21 
[22] Pedersen SS, Hoogwegt MT, Jordaens L, Theuns DAMJ. Pre implantation psychological functioning preserved in majority of implantable cardioverter defibrillator patients 12 months post implantation. International Journal of Cardiology. 2011. In press. http://dx.doi.org/10.1016/j.ijcard.2011.10.092

[23] Steinberg JS, Arshad A, Kowalski M, Kukar A, Suma V, Vloka M, et al. Increased incidence of life-threatening ventricular arrhythmias in implantable defibrillator patients after the World Trade Center attack. Journal of the American College of Cardiology. 2004 9/15; 44(6): 1261-1264.

[24] Shedd OL, Sears Jr SF, Harvill JL, Arshad A, Conti JB, Steinberg JS, et al. The World Trade Center attack: Increased frequency of defibrillator shocks for ventricular arrhythmias in patients living remotely from New York City. Journal of the American College of Cardiology. 2004 9/15; 44(6): 1265-1267.

[25] Ladwig K, Baumert J, Marten-Mittag B, Kolb C, Zrenner B, Schmitt C. Posttraumatic Stress Symptoms and Predicted Mortality in Patients With Implantable Cardioverter-Defibrillators: Results From the Prospective Living With an Implanted Cardioverter-Defibrillator Study. 2008 November 1; 65(11): 1324-1330.

[26] Lazarus RS. Emotion and adaptation. New York: Oxford University Press; 1991.

[27] Izard CE. The psychology of emotions. New York: Plenum; 1991.

[28] Plutchik R, Kellerman H. Theories of emotion. New York: Academic Press; 1980.

[29] Plutchik R. Emotion: a psychoevolutionary synthesis. New York, N.Y.: Harper \& Row; 1980.

[30] Berg S, Svendsen J, Zwisler A, Pedersen B, Preisler P, Siersbaek-Hansen L, et al. COPE-ICD: A randomised clinical trial studying the effects and meaning of a comprehensive rehabilitation programme for ICD recipients -design, intervention and population. BMC Cardiovascular Disorders. 2011; 11(1): 33. PMid:21682864 http://dx.doi.org/10.1186/1471-2261-11-33

[31] World Medical Associaltion Declaration of Helsinki: ethical principles for medical research involving human subjects. JAMA. 2000; 284(23): 3043. PMid:11122593 http://dx.doi.org/10.1001/jama.284.23.3043

[32] Waltz CF, Strickland OL, Lenz ER. Measurement in nursing and health research. 3. ed. ed. New York: Springer; 2005.

[33] Carroll SL, Arthur HM. A comparative study of uncertainty, optimism and anxiety in patients receiving their first implantable defibrillator for primary or secondary prevention of sudden cardiac death. International Journal of Nursing Studies. 2010; 47(7): 836-845.

[34] Thomas SA, Friedmann E, Kelley F. Living With an Implantable Cardioverter-Defibrillator: A Review of the Current Literature Related to Psychosocial Factors. AACN Clinical Issues: Advanced Practice in Acute \& Critical Care. Cardiovascular Nursing. 2001 February; 12(1): 156-163.

[35] Goldstein N, Mehta D, Siddiqui S, Teitelbaum E, Zeidman J, Singson M, et al. "That's Like an Act of Suicide" Patients' Attitudes Toward Deactivation of Implantable Defibrillators. Journal of General Internal Medicine. 2008; 23(08848734): 7-7-12.

[36] Flemme I, Bolse K, Ivarsson A, Jinhage B, Sandstedt B, Edvardsson N, et al. Life situation of patients with an implantable cardioverter defibrillator: a descriptive longitudinal study. Journal of Clinical Nursing. 2001; 10(4): 563-572.

[37] Kamphuis H, Verhoeven N, de Leeuw R, Derksen R, Hauer R, Winnubst J. ICD: a qualitative study of patient experience the first year after implantation. Journal of Clinical Nursing. 2004; 13(8): 1008-1016.

[38] Stramba-Badiale M. Women and research on cardiovascular diseases in Europe: A report from the European Heart Health Strategy (EuroHeart) project. European heart Journal. 2010; 31(14): 1677-1681+1681a-1681d.

[39] Bostwick JM, Sola CL. An updated review of implantable cardioverter/defibrillators, induced anxiety, and quality of life. Psychiatric Clinics of North America. 2007; 30(4): 677-688.

[40] Whang W, Albert CM, Sears Jr SF, Lampert R, Conti JB, Wang PJ, et al. Depression as a predictor for appropriate shocks among patients with implantable cardioverter-defibrillators: Results from the Triggers of Ventricular Arrhythmias (TOVA) study. Journal of the American College of Cardiology. 2005; 45(7): 1090-1095.

[41] Luyster FS, Hughes JW, Waechter DJ, Richard. Resource Loss Predicts Depression and Anxiety Among Patients Treated With an Implantable Cardioverter Defibrillator. Psychosomatic Medicine. 2006 September/October; 68(5): 794-800. PMid:17012535 http://dx.doi.org/10.1097/01.psy.0000227722.92307.35

[42] Spindler H, Johansen JB, Andersen K, Mortensen P, Pedersen SS. Gender differences in anxiety and concerns about the cardioverter defibrillator. Pacing \& Clinical Electrophysiology. 2009; 32(5): 614-621.

[43] Mauro A. Exploring uncertainty and psychosocial adjustment after cardioverter defibrillator implantation. Journal of Cardiovascular Nursing. 2008; 23(6): 527-535.

[44] Sears SF, Lewis TS, Kuhl EA, Conti JB. Predictors of Quality of Life in Patients with Implantable Cardioverter Defibrillators. Psychosomatics. 2005 Sep/Oct; 46(5): 451. PMid:16145190 http://dx.doi.org/10.1176/appi.psy.46.5.451 